\title{
REPRESIÓN, POLÍTICAS DE DEFENSA Y CONTRAINSURGENCIA EN LA ARGENTINA: UN ESTADO DE LA CUESTIÓN (1955-1976)
}

\author{
Defense and counterinsurgency policies in Argentina between 1955 and 1976: \\ a state of the art
}

\author{
Esteban Pontoriero* \\ https://orcid.org/0000-0003-1923-4686
}

\section{Resumen}

El presente artículo expone el estado del arte sobre dos aspectos vinculados que han sido objeto de una gran atención en los estudios sobre represión en la historia reciente Argentina: las políticas de defensa y la doctrina contrainsurgente del Ejército argentino entre 1955 y 1976. En este sentido, en la primera parte se realiza un estudio crítico de la bibliografía que se abocó a explorar las políticas de defensa. En la segunda parte se estudia el desarrollo de los trabajos dedicados a la doctrina antisubversiva del Ejército. En las consideraciones finales se retoman los ejes centrales del artículo, al tiempo que se plantean cuáles son las áreas de vacancia de la historiografía en vistas de continuar avanzando en el conocimiento del pasado de represión de la Argentina de los años sesenta y setenta.

\section{$<$ Historia Reciente $><$ Represión $><$ Defensa $><$ Contrainsurgencia $>$}

\begin{abstract}
The present article exposes the state of the art on two related aspects that have been object of a great attention in the studies on repression in the recent Argentine history: the defense policies and the counterinsurgent doctrine of the Argentine Army between 1955 and 1976. In this sense, in the first part a critical study of the bibliography that was devoted to explore the defense policies is carried out. In the second part the development of the works dedicated to the anti-subversive doctrine of the Army is studied. In the final considerations the central axes of the article are retaken, while the vacancy areas of the historiography are raised in order to continue advancing in the knowledge of the repressive past of Argentina in the sixties and seventies.
\end{abstract}

$$
<\text { Recent history }><\text { Repression }><\text { Defense }><\text { Counterinsurgency }>
$$

Recibido: 01/03/2019

Aceptado: 06/05/2019

\footnotetext{
* Instituto de Altos Estudios Sociales (IDAES), Universidad Nacional de San Martín. Becario Posdoctoral del Consejo Nacional de Investigaciones Científicas y Técnicas (CONICET), Argentina, estebanpontoriero@hotmail.com
} 


\section{Introducción ${ }^{1}$}

Desde el retorno de la democracia a la Argentina, a comienzos de los años ochenta, se registran dos fenómenos que durante mucho tiempo han marcado los abordajes del pasado de represión y violencia política de los años sesenta y setenta. En principio, las historias generales del período 1955-1976 se articularon en torno a dos pares de estructuras dicotómicas predominantes: la que opone actores político-civiles a militares y la que contrasta gobiernos constitucionales con regímenes de facto. De esta forma, si bien los trabajos de Svampa (2003), Tcach (2003), De Riz (2007), Cavarozzi (2009), Halperín Donghi (2010) y Novaro (2010), entre otros, lograron poner de relieve un conjunto de elementos destacados como, por ejemplo, la inestabilidad del sistema político y la alternancia entre civiles y militares en el poder, este enfoque ocluyó la posibilidad de explorar el entramado de discursos y prácticas represivas de estos años. Por este motivo, tal vez, en los trabajos mencionados predomina la tendencia a analizar las características de cada gobierno sin establecer sus interrelaciones. Esa labor hubiera permitido mostrar que, aunque no se eliminan, en algunos casos las divisiones polares mencionadas deben relativizarse como claves de comprensión en beneficio de otras que muestren las vinculaciones y continuidades entre actores y períodos de gobierno. Por consiguiente, los elementos represivos que expresan un avance del actor castrense en la esfera interna se han asociado predominantemente con los regímenes militares, dejándose de lado la búsqueda de las posibles líneas de continuidad con las presidencias constitucionales. $^{2}$

Otro aspecto que debe ponerse a consideración es el que señalan Franco (2012, pp. 15-17) y Águila (2013, pp. 97-99), a saber, que la atención de los investigadores en muchos casos ha estado condicionada por la represión brutal y masiva implementada bajo la última dictadura militar (1976-1983), enfocándose más en este tema y descuidando el estudio de los años previos. En efecto, la magnitud y las características inéditas que tuvieron las prácticas de violencia y exterminio, el robo de bebés, los crímenes comunes integrados a la estructura represiva y el extendido exilio político, produjeron un quiebre que ha llegado a condicionar la interpretación de la historia argentina del siglo XX. De esta forma, en lugar de insertar esas acciones en una trama histórica de más larga data, se tendió a aislarlas y volverlas un umbral de separación respecto del período anterior. No obstante, cabe remarcar que esto se encuentra lejos de ser una especificidad local: como lo muestran Burucúa y Kwiatkowski (2014, pp. 33-38), los procesos de violencia masiva conllevan enormes dificultades para representar, explicar y comprender lo ocurrido. De acuerdo con este planteo, la ruptura abrupta de las cadenas causales de las masacres y genocidios es un fenómeno experimentado tanto por los contemporáneos, así como por quienes producen relatos académicos, memoriales y representaciones artísticas. Por consiguiente, con el objetivo de superar estos limitantes del análisis histórico es necesario avanzar en una agenda de investigación orientada a reinsertar la

1 Deseo expresar mi agradecimiento a los evaluadores anónimos por sus sugerencias y comentarios. Naturalmente, ninguno de ellos es responsable de posibles omisiones y errores.

2 A lo sumo, en los trabajos citados se remarca el carácter represivo de los últimos gobiernos peronistas de la década del setenta, dejando de lado el análisis de sus antecedentes más allá de 1973. 
represión ejecutada con posterioridad a 1976 en una trama más larga. En este sentido, algunos importantes pasos ya se están dando.

En los últimos años, en el campo de la historia reciente, los estudios sobre represión se han ido consolidando como uno de los ámbitos más dinámicos y en expansión. Su vitalidad puede constatarse a través de una gran cantidad de ponencias, artículos académicos, tesis de grado y posgrado junto a una serie de libros escritos por diversos autores. También se expresa en la organización de jornadas, eventos, mesas de congresos académicos y en la formación de diferentes espacios de debate y trabajo en proyectos de investigación en universidades nacionales. Se caracteriza, además, por una marcada preocupación concerniente a la renovación de los problemas históricos, los marcos teóricos y los abordajes metodológicos, un proceso que se ha visto favorecido por la asidua renovación de la documentación y los archivos disponibles (Bohoslavsky, 2016, pp. 23-41; Franco y Lvovich, 2017; Águila, 2018a).

En vistas de estos avances, en conexión con un abordaje desde los estudios sobre represión, este artículo presenta un estado del arte exhaustivo sobre dos aspectos vinculados que han sido objeto de una gran atención: las políticas de defensa y la doctrina contrainsurgente del Ejército argentino entre 1955 y 1976. En este sentido, en la primera parte se realiza un estudio crítico de la bibliografía que explora las políticas de defensa. En la segunda parte, se analiza el desarrollo de los trabajos dedicados a la doctrina antisubversiva del Ejército. En las consideraciones finales se retoman los ejes centrales del artículo, al tiempo que se plantean cuáles son las áreas de vacancia de la historiografía, para continuar avanzando en el conocimiento del pasado de represión de la Argentina de los años sesenta y setenta.

\section{Políticas de defensa}

Para empezar a ordenar la bibliografía según su ámbito de producción, y sin descartar cruces entre unos y otros, puede decirse que los trabajos abocados a las políticas de defensa en la Argentina entre 1955 y 1976 se dividen en cuatro grupos: el militar, el jurídico, el vinculado a diversos organismos de derechos humanos y el académico. A pesar de las diferencias concernientes a sus objetivos, enfoques teórico-metodológicos y bases documentales, derivadas en gran medida de sus contextos institucionales y temporales de producción, todos ellos comparten la prioridad otorgada al análisis de la legislación de defensa elaborada y sancionada en esos años. Este es un punto a remarcar, ya que ha sido continuado por las investigaciones que siguieron: en efecto, el estudio de la normativa permite explorar la forma en la que los diferentes gobiernos pensaron la guerra, el o los enemigos, las amenazas internas y externas, las medidas a implementar para la defensa de la "seguridad nacional" y los argumentos para sostener la imposición de un estado de excepción.

Los análisis llevados adelante por autores militares o especialistas civiles afines al sector castrense se caracterizaron por partir de una valoración positiva de las políticas de defensa que incorporaban la seguridad. Efectivamente, se señalaba que en el contexto de la Guerra Fría la defensa nacional no podía circunscribirse 
estrictamente a su aspecto militar, sino que era necesario tener una comprensión global de los enfrentamientos armados, incluyendo la preparación para una guerra interna. Este argumento se complementaba con una opinión según la cual en la Argentina de los años sesenta y setenta habría tenido lugar un conflicto armado irregular contra la "subversión". Los trabajos de oficiales como Cuesta (1960), el asesor francés Nougués (1962), Barbieri (1967), Arana (1972a; 1972b; 1973a; 1973b; 1974), Álvarez (1986), Villegas (1989), Cáceres (1995) y Martínez (1996; 1998) se posicionan en esta línea. En la misma línea, lo hacen los de los especialistas en temas militares Alcorta (1977) y Fraga $(1988 ; 2002)$. En estos estudios el foco de atención ha estado puesto en comentar la legislación de defensa, con especial énfasis en el Plan de Conmoción Interna del Estado (CONINTES), dictado durante la presidencia de Arturo Frondizi (1958-1962), y la Ley 16.970 de Defensa Nacional de 1966, sancionada en el gobierno de facto del general Juan Carlos Onganía (1966-1970), aunque algunos otros también agregaron los decretos de 1975 de "aniquilamiento de la subversión" de tiempos de María Estela Martínez de Perón (1974-1976). ${ }^{3}$

Debido a la trayectoria de los autores, sin embargo, estos abordajes tienen una fuerte identificación con el actor castrense y, más aún, con un aspecto específico: el enfoque contrainsurgente - es decir, de guerra interna- de la seguridad. Por consiguiente, la evaluación de la legislación de defensa se realizó desde los mismos supuestos doctrinarios del Ejército, a saber, que entre 1955 y 1976 en la Argentina tuvo lugar un enfrentamiento armado desencadenado por la "subversión" en el que las fuerzas militares debieron tomar parte en acciones de combate. Esta interpretación condujo a los analistas a estudiar la legislación desde un acercamiento normativo, basado en medir cuán cerca o cuán lejos de un abordaje antisubversivo se hallaban las diferentes leyes de defensa estudiadas. Además, la asimilación de la represión a una operación bélica, y el silencio frente a las acciones criminales junto con su interpretación general, hacen que este abordaje sea no sólo académicamente equivocado sino también política y éticamente inaceptable. Una excepción dentro de este espacio es D'Andrea Mohr (1999), quien en un trabajo pionero planteó la conexión entre represión, excepcionalidad jurídica y contrainsurgencia, pero sólo a partir de la Ley de Defensa Nacional 16.970 y los decretos de "aniquilamiento de la subversión" de 1975. En este sentido, como muestran varios de los autores académicos que serán comentados más adelante, la construcción en las políticas de defensa y la doctrina militar de una situación de guerra interna fue la precondición para habilitar el ingreso de las Fuerzas Armadas (FF.AA.) en la represión de diversos actores individuales y colectivos que expresaban diferentes formas de la conflictividad político-social.

Por su parte, los trabajos realizados por especialistas del campo del Derecho y los analistas de temas de políticas de defensa dirigieron su atención a una crítica de la normativa del período, poniendo el foco en la ambigüedad jurídica que encontraron en la fusión de los conceptos de defensa nacional y seguridad. En relación con esto,

3 Estos decretos son el 261, el 2.770/75, el 2.771/75 y el 2.772/75. Ver Ministerio de Justicia y Derechos Humanos de la Nación, 2012. 
basados centralmente en el estudio de la Ley de Defensa Nacional 16.970 de tiempos de Onganía, los trabajos de Ugarte (1990; 2004) y Sain (2010) destacaron los potenciales desbordes autoritarios y represivos. En efecto, se destaca que la normativa disponía el uso de las FF.AA. para la represión basada en la falta de definiciones claras tanto acerca de la situación que habilitaría tal intervención, así como en la caracterización del "enemigo interno". Al igual que los trabajos académicos que se comentarán más adelante, la atención otorgada en estos trabajos a la relación de la normativa con las doctrinas militares de guerra interna ha resultado central. En este sentido, una gran parte del esfuerzo de las investigaciones se orienta a mostrar los vínculos e interconexiones entre los espacios de las políticas de defensa de los gobiernos y la doctrina contrainsurgente del Ejército. No obstante, los textos de Ugarte y Sain no profundizan sus análisis a lo largo de todo el período 1955-1976, priorizando el estudio de una sola Ley, la 16.970 de 1966, sin plantear una historia más larga de las políticas de defensa de tiempos de la Guerra Fría. Así, se podrían trazar puntos de contacto con normativas y períodos de gobierno previos y posteriores, borrando la supuesta originalidad y excepcionalidad de la ley de defensa de Onganía e insertándola en una serie de leyes y decretos que se inician en la presidencia de Frondizi y llegan hasta 1976. A su vez, estos trabajos no poseen un análisis específico de la doctrina militar contrainsurgente, por lo que se asimila tal vez de manera muy automática el contenido de la normativa de defensa sancionada por Onganía a un conjunto de principios extraídos del abordaje proveniente de Estados Unidos. De esta forma, se produce una desconexión entre el estudio de las políticas de defensa en sus intercambios con el pensamiento doctrinario del actor castrense.

Con respecto al espacio de producción vinculado a los organismos de derechos humanos, las líneas matrices se organizaron en torno a que el terrorismo de Estado se basó en la aniquilación física de los opositores, así como en la desarticulación de la sociedad civil y política. Desarrolladas desde los comienzos de la última dictadura, las investigaciones de Duhalde (1999), Mignone y Conte Mc Donnell (2006) y la Comisión Argentina de los Derechos Humanos (CADHU, 2014), se orientaron a demostrar el carácter criminal de la acción represiva comandada por las FF.AA. En este sentido, de manera contemporánea a los hechos existía una clara voluntad de visibilizar la metodología clandestina, las desapariciones forzadas y las torturas, entre otros crímenes. En ese contexto, los trabajos producidos por destacados intelectuales se adelantarían en varias décadas a los actuales estudios sobre represión, dejando asentadas importantes líneas que se profundizarían en el futuro: la dualidad entre un marco legal y una ejecución de la represión marcada por los actos ilegales; la necesidad de insertar la violencia represiva de los años setenta en un ciclo más vasto, que llegaba al menos hasta 1955. Derivado de lo anterior, la importancia de examinar el papel de los gobiernos constitucionales (y no sólo las dictaduras) en la construcción de regímenes de excepción, en paralelo con el desarrollo de una doctrina antisubversiva por parte del Ejército.

Las limitaciones, en este caso, provienen especialmente del hecho de que el objetivo central de los autores mencionados no era tanto producir textos de investigación académica, sino elaborar poderosas obras de denuncia de los crímenes dictatoriales. 
Efectivamente, en medio de la recolección de testimonios y documentos para constituir futuras pruebas judiciales, la prioridad estaba puesta en hacer visibles las acciones de violencia masiva y exterminio que el gobierno militar se ocupaba de ocultar. Por ello, las importantes elaboraciones sobre el carácter de la represión clandestina, que luego fueron retomadas por los estudios actuales, podrían ser exploradas en mayor profundad y sistematicidad agregando el uso de una base documental actualmente disponible. Así, por ejemplo, la legislación de defensa no ocupa un lugar central, priorizándose el estudio de otras normativas represivas. Lo mismo ocurre con el análisis de la doctrina antisubversiva del Ejército: si bien se realizan destacadas constataciones, como la influencia ejercida por Francia y Estados Unidos, ésta no ocupa un lugar relevante ni su exploración se lleva a cabo a partir de fuentes primarias, seguramente de difícil acceso en ese tiempo y afortunadamente disponibles en muchos casos hoy en día.

En relación con el grupo de investigaciones realizadas desde el campo académico, las producciones encaradas por estudiosos locales y extranjeros centraron su interés en el abordaje de las políticas de defensa a la luz de sus contextos históricos de producción, intentando ver sus implicancias represivas. En esta línea, los trabajos de López (1985; 1987), Rock (1993), Potash (1994a; 1994b), Rouquié (1998) y Périès (1999; 2004; 2009) se distinguen por estudiar dos normativas específicas: el Plan CONINTES y la Ley de Defensa Nacional 16.970. Con respecto a la primera, se analizaron las medidas represivas, que incluyeron el uso de las fuerzas militares en el orden interno, a la luz de la doctrina antisubversiva de origen francés incorporada por el Ejército algunos años antes. En relación con la segunda, el contenido de la normativa sancionada por Onganía se consideró la primera adaptación local de la doctrina contrainsurgente estadounidense. Estos trabajos, que son de suma relevancia y conforman el punto de partida para un enfoque preocupado por estudiar la legislación de defensa en sus cruces con el marco doctrinario antisubversivo del Ejército, también poseen algunas limitaciones. Debe indicarse que, a excepción de Périès, ninguno de los autores mencionados hizo de las políticas de defensa y sus vínculos con el estado de excepción su eje de análisis. En efecto, sus obras se dedicaron a estudiar la historia política del Ejército entre 1955 y 1976 y/o sus vínculos con el nacionalismo católico, sin atender a la legislación de defensa a lo largo de todo este período. A causa de ello, se produjeron importantes huecos en la reconstrucción de las políticas de defensa. Por ejemplo, los años 1973-1976 están ausentes de las coyunturas analizadas, siendo que se trata de una etapa fundamental.

No obstante, desde tiempos más recientes los estudios sobre la represión política han cobrado un fuerte impulso, destacándose diversas investigaciones sobre la legislación de defensa y los discursos alineados con el pensamiento contrainsurgente durante distintas fases del período 1955-1976. En relación con esto, las obras de Pittaluga (2006), Ranalletti (2009), Eidelman (2010), Águila (2013; 2018b), D’Antonio (2018), Franco (2012a; 2012b; 2016) y mis propios aportes (Pontoriero: 2016a; 2017) exploran la conformación de un entramado de discursos, leyes, decretos y prácticas represivas -algunas de ellas realizadas por vías clandestinas- durante los gobiernos peronistas de la década del setenta, trazando líneas de continuidad con períodos anteriores como, por 
ejemplo, los años de Frondizi y la "Revolución Argentina" (1966-1973). Desde el punto de vista de estos autores, pues, en distintos momentos entre 1955 y 1976 se habilitó la instalación de un estado de excepción en el que el Ejército desarrolló su tarea represiva.

Como se desprende de la comparación con los trabajos mencionados más arriba, en especial las producciones de Franco, Ranalletti y Águila habilitaron el camino para empezar a integrar períodos que antes se encontraban fragmentados o poco estudiados. En contrapartida, la prioridad otorgada a los años 1973-1976, descuidados hasta la aparición de estas investigaciones, generó un desnivel respecto de lo que se conoce de los gobiernos anteriores. En efecto, la mayor parte de los trabajos mencionados se ocuparon menos de estudiar las presidencias de facto de la "Revolución Libertadora" y la "Revolución Argentina" y las presidencias constitucionales de Arturo Frondizi y Arturo Illia (1963-1966).

A su vez, a estos trabajos se suman un conjunto de estudios de caso desarrollados en diferentes provincias y ciudades argentinas. En líneas generales, los textos de Águila (2008; 2017; 2018b), Rodríguez Agüero (2013), Zapata (2014), Barragán (2015), Besoky (2016), Merele (2016), Scatizza (2016) y Montero (2017), entre otros, examinaron las dinámicas de la violencia política y la represión estatal y paraestatal en una escala local. Primordialmente, se abordaron problemas generales a partir de los diferentes casos, destacándose el estudio de las relaciones entre actores civiles y estatales y entre actores estatales y paraestatales. Por su parte, mediante el trabajo etnográfico con militares de distintos rangos, desde el campo de la antropología social se tendió a reconstruir la racionalidad del actor castrense. De esta forma, Garaño $(2012 ; 2015 ; 2016)$ ha mostrado cómo desde febrero de 1975, con el inicio del "Operativo Independencia" (19751977) en Tucumán, el Ejército construyó el "monte tucumano" como aquel "teatro de operaciones" en el que muchos militares "sacrificaron" sus vidas en la llamada "guerra contra la subversión”. Según este autor, luego del golpe de Estado de 1976 esas acciones sirvieron para comprometer a otros miembros de la fuerza en el entramado represivo. En esa línea, otros trabajos más recientes muestran que las memorias de las tropas del "Operativo" permiten entender la manera en que se construyó al enemigo a través de la producción de fuertes emociones y sentimientos de miedo, terror y odio que los volvieron capaces de cometer crímenes brutales (Salvi y Garaño, 2014). Al igual que los trabajos de Pittaluga, Ranalletti, Eidelman, Águila y Franco, estas investigaciones comparten un interés por complejizar la cronología de la represión, buscando las líneas de continuidad entre los gobiernos constitucionales y dictatoriales, entre los actores político-civiles y militares y prestando atención a los borrosos límites existentes entre la legalidad y la ilegalidad dentro de un marco de excepción.

\section{Ejército y contrainsurgencia}

En contraposición al variado campo de los estudios sobre las políticas de defensa revisitado hasta aquí, los trabajos enfocados en la doctrina y la preparación antisubversivas del Ejército argentino en los años 1955-1976 se circunscriben principalmente al área académica. Fundamentalmente, estas obras permitieron conocer 
los motivos de la adopción de un enfoque contrainsurgente por parte del arma terrestre a fines de los años cincuenta, cuáles fueron las escuelas de "guerra antisubversiva" que lo influenciaron, cómo se operó el traspaso de la hegemonía de una de ellas a la otra, de qué forma se propagaron las nuevas ideas dentro de la institución, cómo se establecieron los vínculos con las misiones militares extranjeras y cuáles fueron las implicancias del abordaje antisubversivo.

Por un lado, un conjunto de trabajos se dedicaron a estudiar el proceso de incorporación de la doctrina francesa "de la guerra revolucionaria" (DGR) en las filas del Ejército argentino y el comienzo de la elaboración de un saber contrainsurgente local entre 1957 y 1962. En relación con esto, autores como López (1985; 1987), Rock (1993), Castagnola (1994), García (1995), Amaral (1998), Rouquié (1998), Llumá (2002), Mazzei (2002; 2012), Oliveira-Cézar (2002), Robin (2005) y Ranalletti (2007; 2009 ; 2011) ordenaron sus exposiciones a partir de la separación analítica entre una teoría y una serie de métodos. En efecto, estos especialistas señalaron que la DGR brindó un marco de interpretación basado en el diagnóstico de una guerra total —militar, pero también política, económica y cultural- entre el bloque occidental, en el que se incluía a la Argentina, y el bloque comunista; un enfrentamiento que se desarrollaba al interior de las fronteras y había sido iniciado por la Unión Soviética con el ánimo de extender su predominio en diversas partes del mundo. Asimismo, la "doctrina francesa" prescribía un conjunto de medidas basadas en el control de la población, la subordinación de las fuerzas de seguridad al mando castrense y en habilitar la realización de actos criminales asimilados a acciones de guerra contra un "enemigo interno". Estos trabajos destacan, a su vez, que la influencia de la DGR se extendió a los años siguientes, constituyendo una de las bases doctrinarias de la represión clandestina comandada por las FF.AA. en los años setenta.

Por el otro, un grupo de estudios abordaron la adopción de la doctrina "de la seguridad nacional" estadounidense (DSN) por el arma terrestre argentina desde mediados de los años sesenta. En este sentido, los trabajos de López (1987), Rock (1993), García (1995), Rouquié (1998), Marchak (1999), Andersen (2000), Oliveira-Cézar (2003), Mazzei (2012) y Divinzenso (2016a; 2016b) resaltaron los motivos por los que se adoptó la doctrina estadounidense como guía, el papel decisivo desempeñado por un grupo de altos oficiales del arma de caballería, la incorporación de un enfoque contrainsurgente vinculado a los conceptos de seguridad y desarrollo, y la adopción de la "acción cívica" como una tarea primordial en la lucha contra las fuerzas del "comunismo". Asimismo, en vez de plantear el reemplazo de una doctrina por otra, estos autores prefieren hablar de un proceso de fusión de las matrices de contrainsurgencia francesa y estadounidense que desde la década del setenta permitiría al arma terrestre avanzar definitivamente hacia la construcción de un saber antisubversivo propio. A su vez, una serie de producciones enfocadas en la doctrina y la preparación antisubversivas del Ejército exploraron los años previos al golpe militar de marzo de 1976, comenzando en 1973. No obstante, debe aclararse que en este punto los trabajos continúan siendo mucho más escasos que los dedicados a etapas anteriores. En relación con esto, los textos de Slatman (2010), Jemio 
(2013a; 2013b), de Maio (2016), Fraga (1988) y Ranalletti (2007; 2009) se propusieron extender la exploración más allá de la "Revolución Argentina", aunque enfocándose centralmente en el actor militar y dejando en segundo plano u omitiendo el estudio de los vínculos entre la doctrina y un marco legal de excepción.

En relación con esto, tal vez el motivo principal de la falta de más trabajos dedicados al estudio de los años 1973-1976 se vincula con las dificultades de acceso a una gran parte de la documentación. ${ }^{4}$ En efecto, muchas veces ésta se encuentra retirada de los archivos castrenses debido al requerimiento judicial en causas por crímenes de lesa humanidad y/o a su destrucción u ocultamiento por parte de los hombres de armas. También puede agregarse otra posible explicación, no ya del orden de la carencia de fuentes sino vinculada al enfoque predominante: la preocupación por estudiar dos etapas claramente diferenciadas por el predominio de la DGR en un caso (1957-1962) y la DSN en el otro (1966-1973). Derivado de esto, el análisis de los años 1973-1976 quedó descuidado o asimilado con una extensión del panorama doctrinario de tiempos de la "Revolución Argentina". Así, se perdió la posibilidad de explorar esta etapa de profundización y sistematización de los saberes incorporados en años anteriores, sumada a una serie de desarrollos bastante novedosos que hablan de una madurez y asentamiento de las ideas antisubversivas locales. De igual forma que con los estudios sobre las políticas de defensa, las investigaciones sobre la doctrina contrainsurgente muestran la falta de un abordaje que cubra el período 1955-1976 en toda su extensión, comparando y estableciendo líneas de continuidad y cambio a través de los años o nuevos desarrollos que se incorporan junto a otros que se abandonan. Lo mismo ocurre con respecto a la normativa de defensa en relación con la doctrina antisubversiva: no se registra un acercamiento que abarque la porción de tiempo comprendida entre 1955 y 1976, produciéndose aquí también un análisis fragmentado que obtura la reconstrucción del vínculo orgánico que mantuvieron las políticas de defensa con la doctrina militar contrainsurgente.

Es importante destacar que, así como los estudios académicos sobre las políticas de defensa revisitados previamente establecieron vínculos con la doctrina antisubversiva del Ejército, los trabajos abocados a esta segunda cuestión también incorporaron el estudio de la normativa de defensa, por lo que en este caso también se propuso abordar las interconexiones entre los campos político-civil y castrense. Este enfoque ayuda a estudiar la inclusión de la seguridad dentro del área de la defensa mediante la exploración de las políticas de defensa y sus relaciones de intercambio permanente con la doctrina antisubversiva. Asimismo, otra cuestión que ha servido para orientar a muchos investigadores ha sido la particular atención otorgada por estos trabajos al análisis de las publicaciones castrenses, convirtiéndose en su principal insumo documental para reconstruir la doctrina castrense por medio de revistas, reglamentos y libros. En efecto, a pesar de ciertos faltantes de los archivos y bibliotecas militares, estos materiales junto a otros como, por ejemplo, directivas, órdenes y ejercicios de guerra permiten sistematizar una serie documental que cubre el período 1955-1976 y abren

\footnotetext{
4 En parte, intenté abordar este período en Pontoriero (2016).
} 
la posibilidad de comparar, historizar y reconstruir las diferentes configuraciones que atravesó el pensamiento contrainsurgente local.

\section{Consideraciones finales}

Tal como se puede observar, el abordaje contrainsurgente del Ejército y las políticas de defensa desarrolladas por los diferentes gobiernos del período 1955-1976, constituyen dos ejes centrales e interrelacionados de la historiografía sobre represión. En ese sentido, el caso argentino siguió una tendencia ya visible en otras experiencias históricas: el desborde de las premisas de las doctrinas contrainsurgentes hacia el campo de la legislación, introduciendo un enfoque de la guerra interna que entremezclaba la seguridad y la defensa. A su vez, otro aspecto remarcado por varios autores es que la doctrina y planeamientos antisubversivos del Ejército también se nutrieron del marco legal, usándolo como base normativa de sus lineamientos teórico-prácticos para la intervención en seguridad. Derivado de esto, las investigaciones más actuales se orientan a desestabilizar algunas interpretaciones dicotómicas presentes en las historias generales del período. En efecto, como se analizó anteriormente de acuerdo con un conjunto de cientistas sociales, los años en cuestión habrían expresado dos divisiones polares que funcionaron como condicionantes del proceso histórico y factores explicativos: primeramente, la oposición entre civiles-políticos y militares y, a continuación, la diferenciación absoluta entre gobiernos constitucionales y dictaduras militares. A su vez, junto a éstas puede agregarse una tercera disyuntiva, a saber, la separación entre la seguridad interna y la defensa nacional. En este trabajo, sin embargo, se mostró que en la opinión de varios autores esos tres aspectos deben ser profundamente reconsiderados y analizados en sus puntos de contacto, continuidad y realimentación mutua.

Dicho esto, el área de los estudios sobre las políticas de defensa explorado a lo largo de estas páginas muestra una serie de límites, por lo que es necesario abordar en mayor detalle algunos de ellos, planteando además qué aspectos permitirían conocer mejor en futuras investigaciones. En primer lugar, con la excepción de algunos proyectos de ley de defensa de 1960 y 1961, no ha sido posible establecer la autoría de las demás normativas elaboradas durante el período 1955-1976, pudiéndose a lo sumo comprobar la participación en la redacción de miembros de las FF.AA. En segundo lugar, no se pudo avanzar plenamente sobre los motivos por los que algunos de los proyectos fracasaron en su tratamiento en el Congreso o no llegaron siquiera a ser enviados y discutidos en esa instancia.

En relación con esto, la inexistencia de un archivo que conserve los debates internos de las comisiones de Defensa de las cámaras de Diputados y Senadores tal vez explique en parte los problemas para ir más allá en este terreno. De encontrase disponible esa documentación, quizás se pueda dar cuenta de los acuerdos y desacuerdos presentes entre los miembros de la dirigencia política respecto del abordaje contrainsurgente de la seguridad interna a lo largo de las diferentes coyunturas estudiadas. En este sentido, la indagación de estas cuestiones permitiría saber más acerca de los grados y formas de penetración de las nociones provenientes de las doctrinas castrenses de "guerra antisubversiva" en el ámbito político-civil. A su vez, este aspecto brindaría 
claves para profundizar en el estudio de las vinculaciones entre los actores políticociviles y castrenses al momento de delinear una política de defensa con un enfoque contrainsurgente. En general, sobre estas cuestiones puede decirse que, hasta donde los trabajos reseñados lo permiten, se puede ver una profunda interconexión entre dirigentes políticos y autoridades militares. En efecto, esta perspectiva compartida se manifestó tanto en el uso de un conjunto de conceptos, métodos y argumentos justificatorios para la represión interna, así como en la participación directa de civiles junto a representantes de las FF.AA. en la elaboración, discusión y/o implementación de distintos cursos de acción antisubversivos. Asimismo, en el Congreso puede constatarse cómo una serie de legisladores de diversos partidos políticos también apoyaban este enfoque de la seguridad interna, sirviendo para confirmar la extensión de las nociones provenientes de la doctrina militar dentro del ámbito político-civil.

Por su parte, el análisis del abordaje contrainsurgente de la seguridad interna desarrollado por el Ejército en su doctrina y planeamientos operativos en el período 19551976 también muestra algunos aspectos pendientes sobre los que deberá profundizarse. En particular, una cuestión que se lamenta es la imposibilidad hasta ahora de establecer quiénes fueron los redactores de los reglamentos militares de "guerra antisubversiva" y, en la gran mayoría de los casos, cuáles fueron los materiales bibliográficos utilizados para su elaboración. En este sentido, la exploración de estos aspectos permitiría conocer mejor a los hombres de armas detrás de la doctrina y, sobre todo, habría dado mayores certezas respecto de las fuentes desde las que se nutrieron, en especial, las provenientes de Francia y Estados Unidos, pero también podrían haberse agregado las influencias de otros países con los que -se sabe- el Ejército tuvo contactos en los años aquí estudiados (Bélgica o Israel, por ejemplo). A su vez, la clarificación de este asunto hubiera ayudado a dar cuenta de los desarrollos teóricos locales de una manera más certera.

Asimismo, queda pendiente realizar un estudio enfocado en la reconstrucción de los operativos represivos a la luz de los saberes sistematizados en los reglamentos y demás normativas castrenses estudiadas. En efecto, seguramente puedan explorarse los puntos de contacto entre la doctrina y la acción sobre el terreno de los hombres de armas, pero también interesa dar cuenta de los puntos de ruptura, es decir, de aquellas prácticas que no encuentran referencia directa ni prescripción alguna en los reglamentos, órdenes y/o directivas. En relación con esto, a pesar de las líneas de contacto que en muchos casos la historiografía buscó trazar entre la excepcionalidad jurídica y el abordaje contrainsurgente con los mecanismos clandestinos del terrorismo de Estado —con los ejemplos paradigmáticos del exterminio secreto y las desapariciones de los cadáveres de las víctimas - también se deben reconocer ciertos límites. Por un lado, los procesos de violencia masiva producen un quiebre abrupto de las cadenas causales y, por el otro, adquieren una dinámica propia que difícilmente pueda explicarse a partir de sus condiciones de posibilidad. ${ }^{5} 5$ Por consiguiente, el estudio de las prácticas clandestinas de exterminio de la última dictadura militar conforma un espacio de indagaciones específico.

5 Como se señaló en la Introducción, el primer aspecto fue remarcado por Burucúa y Kwiatkowski en un trabajo ya citado. Con respecto al segundo punto ver Sémelin, (2007, pp. 165-237). 
En ambos casos, el de las políticas de defensa y el del abordaje contrainsurgente del Ejército, las problemáticas derivadas del acceso, conservación, ocultamiento o destrucción de las fuentes juegan un rol crucial para habilitar avances en la investigación o dejar puntos oscuros como los señalados más arriba. En efecto, debe destacarse que muchos de los aportes de los diferentes autores reseñados fueron posibles gracias a la recuperación, aparición y/o apertura de nuevos documentos, junto con su organización y catalogación en los archivos en los que fueron depositados. En relación con la legislación de defensa y otros materiales relativos a ella, la posibilidad de disponer para la consulta de acervos como el Fondo del Centro de Estudios Nacionales ubicado en la Biblioteca Nacional de Argentina, que conserva documentos de Frondizi y su gobierno, o la desclasificación de los decretos secretos sancionados por el Poder Ejecutivo en 2013, por ejemplo, ha resultado ser decisiva. A su vez, con respecto a la doctrina castrense de "guerra antisubversiva", la documentación disponible en el Servicio Histórico del Ejército Argentino ha sido de una gran importancia. En relación con esto, debido a que el campo de la historia reciente se caracteriza por la posibilidad siempre latente de nutrirse del hallazgo y la aparición de nuevos documentos y materiales, el conocimiento producido siempre está sujeto a importantes reconsideraciones, reformulaciones y reinterpretaciones que pueden modificar en mayor o menor medida los saberes ya establecidos. Para terminar, así como muchas de las investigaciones revisitadas se beneficiaron de la consulta de archivos y materiales que antes no se encontraban disponibles, no puede descartarse que en el futuro la aparición de nuevos documentos habilite la revisión de algunas de las conclusiones aquí expuestas o permitan completar los vacíos ya mencionados.

\section{Referencias bibliográficas}

Águila, G. (2008). Dictadura, represión y sociedad en Rosario, 1976/1983: un estudio sobre la represión y los comportamientos y actitudes sociales en dictadura. Buenos Aires: Prometeo.

Águila, G. (2013). La represión en la historia reciente argentina: fases, dispositivos y dinámicas regionales. En G. Águila y L. Alonso (comps.), Procesos represivos y actitudes sociales: entre la España franquista y las dictaduras del Cono Sur, (pp. 97-122). Buenos Aires: Prometeo Libros.

Águila, G. (2016). Modalidades, dispositivos y circuitos represivos a escala local/ regional: Rosario, 1975-1983. En G. Águila, S. Garaño y P. Scatizza (comps.), Represión estatal y violencia paraestatal en la historia reciente argentina. Nuevos abordajes a cuarenta años del golpe de Estado, (pp. 353-378). La Plata: Universidad Nacional de La Plata, Recuperado de: http://www.libros.fahce.unlp. edu.ar/index.php/libros/catalog/book/63.

Águila, G. (2018a). La represión en la historia reciente como objeto de estudio: problemas, novedades y derivas historiográficas. En G. Águila et. al. La historia reciente en Argentina. Balances de una historiografia pionera en América Latina, (pp. 55-72). Buenos Aires: Imago Mundi. 
Águila, G. (2018b). Policías, represión y 'lucha antisubversiva': exploraciones sobre el rol de las policías en el accionar represivo de los años 70 en Argentina, Folia Histórica del Nordeste, $\mathrm{n}^{\circ} 32$, pp. 121-146, Recuperado de: http://revistas.unne. edu.ar/index.php/fhn/article/view/3500/3137.

Águila, G. (comp). (2017). Territorio ocupado: la historia del II Cuerpo de Ejército en Rosario: 1960-1990. Rosario: Editorial Municipal de Rosario.

Alcorta, J. A. (1977). Documentos previos a la ley No 16.970, Revista de la Escuela de Defensa Nacional, $\mathrm{n}^{\circ}$ 18, pp. 117-130.

Álvarez, O. A. (1986). Evolución histórica del régimen jurídico de la defensa nacional, Revista Militar, $\mathrm{n}^{\circ}$ 715, pp. 24-41.

Amaral, S. (1998). Guerra revolucionaria: de Argelia a la Argentina, 1957-1962, Investigaciones y Ensayos, $\mathrm{n}^{\circ}$ 48, pp. 173-195, Recuperado de: https://www.academia.edu/7759928/ Samuel_Amaral_Guerra_revolucionaria_de_Argelia_a_la_Argentina_1957-1962_.

Andersen, M. E. (2000). Dossier secreto. El mito de la guerra sucia. Buenos Aires: Planeta.

Arana, J. A. (1972a). Seguridad y Defensa Nacional. Primera Parte, Revista de la Escuela de Comando y Estado Mayor de la Fuerza Aérea Argentina, $\mathrm{n}^{\circ}$ 61, pp. 11-25.

Arana, J. A. (1972b). Seguridad y Defensa Nacional. Segunda Parte, Revista de la Escuela de Comando y Estado Mayor de la Fuerza Aérea Argentina, nº 62, pp. 11-23.

Arana, J. A. (1973a). Seguridad y Defensa Nacional. Segunda Parte. Evolución legal de la defensa nacional en la República Argentina, Revista de la Escuela de Comando y Estado Mayor de la Fuerza Aérea Argentina, nº 67, pp. 29-54.

Arana, J. A. (1973b). Seguridad y Defensa Nacional. Tercera Parte. Evolución legal de la defensa nacional en la República Argentina, Revista de la Escuela de Comando y Estado Mayor de la Fuerza Aérea Argentina, no 68, pp. 11-42.

Arana, J. A. (1974). Seguridad y Defensa Nacional (Cuarta Parte), Revista de la Escuela de Comando y Estado Mayor de la Fuerza Aérea Argentina, no 74, pp. 43-70.

Barbieri, A. (1967). La moderna seguridad. Buenos Aires: Círculo Militar.

Barragán, I. (2015). ¿Quién construye la Nación? Obreros y militares en el Astillero Río Santiago. Procesos de trabajo, violencia y represión (1969-1979), Tesis de Doctorado. Universidad de Buenos Aires.

Besoky, J. L. (2016). La derecha peronista. Prácticas políticas y representaciones (1943-1976). Tesis de Doctorado. Universidad Nacional de La Plata.

Bohoslavsky, E. (2016). Cambios en la historiografía académica en Argentina (20012015), História da Historiografia, $\mathrm{n}^{\circ}$ 20, pp. 102-120, Recuperado de: https:// www.historiadahistoriografia.com.br/revista/article/view/967.

Burucúa, J. E. y Kwiatkowski, N. (2014). “Cómo sucedieron estas cosas”. Representar masacres y genocidios. Buenos Aires: Katz Editores.

Cáceres, G. (1995). La crisis militar argentina. En G. Cáceres y T. Sheetz (comps), Defensa no provocativa. Una propuesta de reforma militar para la Argentina, (pp. 13-54). Buenos Aires: Editora Buenos Aires.

Castagnola, G. (1994). Doctrina y política en el ejército argentino. De la defensa nacional a la guerra revolucionaria (1956-1962). Tesis de Maestría. Universidad Torcuato Di Tella. 
Cavarozzi, M. (2009). Autoritarismo y democracia: 1955-2006. Buenos Aires: Ariel. Comisión Argentina de los Derechos Humanos (CADHU). (2014). Argentina: proceso al genocidio. Buenos Aires: Ediciones Colihue.

Cuesta, R. (1960). Normas integrantes del derecho de guerra aplicables para casos de acción subversiva, Revista de la Escuela Superior de Guerra, n 338, pp. 364-390.

D’ Andrea Mohr, J. L. (1999). Memoria Debida. Buenos Aires: Colihue.

D’ Antonio, D. (comp.). (2018). Violencia, espionaje y represión estatal. Seis estudios sobre el pasado reciente argentino. Buenos Aires: Imago Mundi.

De Maio, A. (2016). Represión estatal y lucha contrarrevolucionaria. Lógicas militares y aplicación de la Doctrina de la Seguridad Nacional en Argentina y Paraguay. En P. Funes (comp.), Revolución, dictadura y democracia. Lógicas militantes y militares en la historia argentina en el contexto latinoamericano, (pp. 59-88). Buenos Aires: Imago Mundi.

De Riz, L. (2007). Historia argentina 8: la política en suspenso: 1966-1976. Buenos Aires: Paidós.

Divinzenso, A. (2016a). La “Acción Cívica” del Comando del II Cuerpo de Ejército. Un estudio de las relaciones cívico-militares en Rosario, 1960-1983. Tesis de Maestría. Universidad Nacional de General Sarmiento.

Divinzenso, A. (2016b). La transformación de las relaciones cívico-militares: la 'Acción Cívica’ del Ejército (1960-1983). En G. Águila, S. Garaño y P. Scatizza (comps.), Represión estatal y violencia paraestatal en la historia reciente argentina. Nuevos abordajes a cuarenta años del golpe de Estado, (pp. 73-102). La Plata: Universidad Nacional de La Plata, Recuperado de: http://www.libros.fahce.unlp. edu.ar/index.php/libros/catalog/book/63.

Duhalde, E. L. (1999). El Estado terrorista argentino. Quince años después. Buenos Aires: Eudeba.

Eidelman, A. (2010). El desarrollo de los aparatos represivos del Estado argentino durante la "Revolución Argentina”, 1966-1973. Tesis de Doctorado. Universidad de Buenos Aires.

Fraga, R. (1988). Ejército: del escarnio al poder (1973-1976). Buenos Aires: Planeta.

Fraga, R. (1992). El Ejército y Frondizi (1958-1962). Buenos Aires: Emecé.

Franco, M. (2012a). Rompecabezas para armar: la seguridad interior como política de Estado en la historia argentina reciente (1958-1976), Contemporánea, $\mathrm{n}^{\circ} 3$, pp. 77 95, Recuperado de: https://dialnet.unirioja.es/servlet/articulo? codigo $=4224576$.

Franco, M. (2012b). Un enemigo para la nación: orden interno, violenciay “subversión”, 1973-1976. Buenos Aires: Fondo de Cultura Económica.

Franco, M. (2016). La represión estatal en la historia argentina reciente: problemas, hipótesis y algunas respuestas tentativas. En G. Águila, S. Garaño y P. Scatizza (comps.), Represión estatal y violencia paraestatal en la historia reciente argentina. Nuevos abordajes a cuarenta años del golpe de Estado, (pp. 17-46). La Plata: Universidad Nacional de La Plata, Recuperado de: http://www.libros. fahce.unlp.edu.ar/index.php/libros/catalog/book/63. 
Franco, M. y D. Lvovich. (2017). Historia Reciente: apuntes sobre un campo de investigación en expansión, Boletín del Instituto de Historia Argentina y Americana "Dr. Emilio Ravignani”, n 47, pp. 190-217, Recuperado de: http:// ppct.caicyt.gov.ar/index.php/ravignani/article/view/11091/pdf_1.

Garaño, S. (2012). Entre el cuartel y el monte. Soldados, militantes y militares durante el Operativo Independencia (Tucumán, 1975-1977). Tesis de Doctorado. Universidad de Buenos Aires.

Garaño, S. (2015). La experiencia de guerra en el 'teatro de operaciones' del Operativo Independencia (Tucumán, 1975-1977). Sacrificios, deudas y compañerismo en el monte tucumano. En F. Lorenz (comp.), Guerras de la historia argentina (pp. 287-312). Buenos Aires: Ariel.

Garaño, S. (2016). Las formas de la represión política en el 'teatro de operaciones' del Operativo Independencia (Tucumán, 1975-1977). En G. Águila, S. Garaño y P. Scatizza (comps.), Represión estatal y violencia paraestatal en la historia reciente argentina. Nuevos abordajes a cuarenta años del golpe de Estado, (pp.129-158). La Plata: Universidad Nacional de La Plata, Recuperado de: http://www.libros. fahce.unlp.edu.ar/index.php/libros/catalog/book/63.

García, P. (1995). El drama de la autonomía militar. Argentina bajo las Juntas Militares. Madrid: Alianza Editorial.

Halperín Donghi, T. (2010). Historia argentina 7: la democracia de masas. Buenos Aires: Paidós.

Jemio, A. S. (2013a). El desarrollo doctrinario del Ejército argentino a través de sus reglamentos (1965-1977). Continuidades y rupturas, XIV Jornadas Interescuelas/ Departamentos de Historia, Universidad Nacional de Cuyo. Recuperado de: https:// www.academia.edu/23250260/El_desarrollo_doctrinario_del_Ej\%C3\%A9rcito_ argentino_a_trav\%C3\%A9s_de_sus_reglamentos_1965-1977_.

Jemio, A. S. (2013b). La construcción del enemigo interno en los reglamentos del Ejército Argentino de las décadas del sesenta y setenta. Continuidades y rupturas, X Jornadas de Sociología de la Facultad de Ciencias Sociales de la Universidad de Buenos Aires. Recuperado de: http://cdsa.aacademica.org/000-038/244.pdf.

Llumá, D. (2002). Los maestros de la tortura, Todo es Historia, no 422, pp. 6-16.

López, E. (1985). Doctrinas militares en Argentina: 1932-1980. En C. Moneta, E. López y A. Romero. La reforma militar (pp. 101-143). Buenos Aires: Legasa.

López, E. (1987). Seguridad Nacional y sedición militar. Buenos Aires: Legasa.

Marchak, P. (1999). God's assassins: state terrorism in Argentina in the 1970s. Quebec: McGill-Queen's Press.

Martínez, C. J. M. (1996). La evolución del pensamiento estratégico en la legislación argentina. Experiencia y futuro. Buenos Aires: Ministerio de Defensa-Escuela de Defensa Nacional, Cuadernos Académicos de la Escuela de Defensa Nacional, no 2 . Martínez, C. J. M. (1998). Medio siglo de estrategia argentina. Buenos Aires: Ministerio de Defensa- Escuela de Defensa Nacional, Cuadernos Académicos de la Escuela de Defensa Nacional, $n^{\circ} 4$. 
Mazzei, D. (2002). La misión militar francesa en la Escuela Superior de Guerra y los orígenes de la Guerra Sucia, 1957-1961, Revista de Ciencias Sociales, $\mathrm{n}^{\circ} 13$, pp. 105-137.

Mazzei, D. (2012). Bajo el poder de la caballería: el ejército argentino 1962-1973. Buenos Aires: Eudeba.

Merele, H. J. (2017). La depuración ideológica del peronismo en General Sarmiento (1973-1974). Una aproximación al proceso represivo durante los años setenta constitucionales a partir del caso de Antonio Tito Deleroni. La Plata, Los Polvorines, Misiones: Universidad Nacional de La Plata, Universidad Nacional de General Sarmiento, Universidad Nacional de Misiones.

Mignone, E. y Conte Mc Donnell, A. (2006). Estrategia represiva de la dictadura militar. La doctrina del paralelismo global. Buenos Aires: Colihue.

Ministerio de Justicia y Derechos Humanos de la Nación. Secretaría De Derechos Humanos. (2012). Documentos del estado terrorista: directiva del comandante general del ejército $n^{\circ} 404 / 75$, lucha contra la subversión, plan del ejército contribuyente al plan de seguridad nacional. Buenos Aires: Ministerio de Justicia y Derechos Humanos de la Nación. Recuperado de: http:/www.jus.gob. ar/media/1129178/41-anm-documentos_del_estado_terrorista.pdf.

Montero, M. L. (2017). La Universidad Nacional del Sur y la trama cívico militar de la represión en Bahía Blanca (1975-1983). Tesis de Doctorado. Universidad Nacional del Sur.

Nougués, J. (1962). Radioscopia subversiva de la Argentina, Revista de la Escuela Superior de Guerra, no 344, pp. 24-43.

Novaro, M. (2010). Historia de la Argentina. 1955-2010. Buenos Aires: Siglo Veintiuno Editores.

Oliveira-Cézar, M. (2002). Las raíces francesas de la guerra antisubversiva, Todo es Historia, $\mathrm{n}^{\mathrm{o}} 422$, pp. 24-34.

Oliveira-Cézar, M. (2003). El aprendizaje de la guerra contrarrevolucionaria, Todo es Historia, $\mathrm{n}^{\mathrm{o}} 435$, pp. 70-80.

Périès, G. (1999). De l'action militaire à l'action politique. Impulsion, codification et application de la doctrine de la "guerre révolutionnaire" au sein de l'Armée française (1944-1960). Tesis de Doctorado. Universidad de París I.

Peries, G. (2004). Un modèle d'échange doctrinal franco-argentin: le Plan CONINTES, 1951-1966. En R. Fregosi (comp.). Armées, pouvoirs en Amérique latine (pp. 19-40). Paris: CREDAL-IHEAL Editions.

Peries, G. (2009). La doctrina militar contrainsurgente como fuente normativa de un poder de facto exterminador basado sobre la excepcionalidad. En D. Feierstein (comp.), Terrorismo de estado y genocidio en América Latina, (pp. 221-247). Buenos Aires: Prometeo Libros.

Pittaluga, R. (2006). La memoria según Trelew, Sociohistórica. Cuadernos del CISH, $\mathrm{n}^{\circ}$ 19-20, pp. 81-111, Recuperado de: http://www.memoria.fahce.unlp.edu.ar/ art_revistas/pr.3610/pr.3610.pdf. 
Pontoriero, E. (2016a). En torno a los orígenes del terror de Estado en la Argentina de la década del setenta: cuándo, cómo y por qué los militares decidieron el exterminio clandestino, Papeles de Trabajo. Revista Electrónica del IDAES, vol. 10, pp. 3050, Recuperado de: https://dialnet.unirioja.es/servlet/articulo? codigo $=5875343$.

Pontoriero, E. (2016b). Preparativos de guerra': Ejército, doctrina antisubversiva y planes represivos en los orígenes del terror de Estado, 1973-1976, Revista Universitaria de Historia Militar, vol. 5, pp. 319-319, en: http://ruhm.es/index. $\mathrm{php} / \mathrm{RUHM} / \mathrm{article} / \mathrm{view} / 226$.

Pontoriero, E. (2017). La seguridad interna como "teatro de guerra": estado de excepción y contrainsurgencia en la Argentina (1955-1976). Tesis de Doctorado. Instituto de Altos Estudios Sociales, Universidad Nacional de San Martín.

Potash, R. (1994a). El Ejército y la política en Argentina. De la caída de Frondizi a la restauración peronista. Primera parte, 1962-1966. Buenos Aires: Sudamericana.

Potash, R. (1994b). El Ejército y la política en Argentina. De la caída de Frondizi a la restauración peronista. Segunda parte, 1966-1973. Buenos Aires: Sudamericana.

Ranalletti, M. (2007). La legitimación de la tortura como herramienta en tareas de inteligencia. Estudio de caso a partir de los reglamentos del Ejército argentino (1968-1976), Segundo Encuentro Internacional de Análisis de las Prácticas Sociales Genocidas, Buenos Aires, Universidad Nacional de Tres de Febrero.

Ranalletti, M. (2009). Contrainsurgencia, catolicismo intransigente y extremismo de derecha en la formación militar argentina. Influencias francesas en los orígenes del terrorismo de Estado (1955-1976). En D. Feierstein (comp.), Terrorismo de estado y genocidio en América Latina, (pp. 249-281). Buenos Aires: Prometeo Libros.

Ranalletti, M. (2011). Una aproximación a los fundamentos del terrorismo de Estado en Argentina: la recepción de la noción de 'guerra revolucionaria' en el ámbito castrense local (1954-1962), Anuario del Centro de Estudios Históricos "Prof. Carlos S. A. Segreti”, n 11, pp. 261-278.

Robin, M. (2005). Escuadrones de la muerte: la escuela francesa. Buenos Aires: Sudamericana.

Rock, D. (1993). La Argentina autoritaria. Buenos Aires: Ariel.

Rodríguez Agüero, L. (2013). Ciclo de protestas, experiencias organizativas y represión paraestatal: Mendoza, 1972-1976. Tesis de Doctorado. Universidad Nacional de La Plata.

Rouquié, A. (1998). Poder militar y sociedad política en la Argentina II. 1943-1973. Buenos Aires: Emecé.

Sain, M. (2010). Los votos y las botas: estudios sobre la defensa nacional y las relaciones civil-militares en la democracia argentina. Buenos Aires: Prometeo Libros.

Salvi, V. y Garaño, S. (2014). Las fotos y el helicóptero. Memorias de oficiales retirados y ex soldados conscriptos que participaron del Operativo Independencia (Tucumán, 1975-1977), Estudios Sociales, n 47, pp. 163-189. Recuperado de: https:// bibliotecavirtual.unl.edu.ar/ojs/index.php/EstudiosSociales/article/view/5092.

Scatizza, P. (2016). Un Comahue violento: dictadura, represión y juicios en la Norpatagonia Argentina. Buenos Aires: Prometeo. 
Sémelin, J. (2007). Purify and destroy: the political uses of massacre and genocide. New York: Columbia University Press.

Slatman, M. (2010). Una doctrina contrarrevolucionaria para el ejército argentino. Análisis de la discursividad oficial del Ejército Argentino durante la Guerra Fría (1957-1976). En García Ferreira, R. (comp.). Guatemala y la Guerra Fría en América Latina (1947-1977), (pp. 431-460). Guatemala: CEUR-USAC. Recuperado de: https:/www.academia.edu/8441533/Una_doctrina_militar_ contrarrevolucionaria_para_la_Naci\%C3\%B3n_Argentina._An $\% \mathrm{C} 3 \% \mathrm{~A} 1$ lisis de_la_discursividad_oficial_del_Ej\%C3\%A9rcito_Argentino_durante_la Guerra_Fr\%C3\%ADa_1957-1976.

Svampa, M. (2003). El populismo imposible y sus actores, 1973-1976. En D. James (comp.), Nueva historia argentina: Violencia, proscripción y autoritarismo $1955-$ 1976 (pp. 381-437). Buenos Aires: Sudamericana, Vol. 9.

Tcach, C. (2003). Golpes, proscripciones y partidos politicos. En D. James (comp.), Nueva historia argentina: Violencia, proscripción y autoritarismo 1955-1976 (pp. 17-61). Buenos Aires: Sudamericana, Vol. 9.

Ugarte, J. M. (1990). Seguridad Interior. Buenos Aires: Fundación Arturo Illia.

Ugarte, J. M. (2004. Los conceptos jurídicos y políticos de la seguridad y la defensa: un análisis orientado a América Latina. Buenos Aires: Plus Ultra.

Villegas, O. (1989). "La llamada doctrina de la Seguridad Nacional", Revista Militar, $\mathrm{n}^{\circ}$ 721, enero, pp. 22-26.

Zapata, A. B. (2014). Andamios de experiencias: conflictividad obrera, vigilancia y represión en Argentina. Bahía Blanca, 1966-1976. Tesis de Doctorado. Universidad Nacional de La Plata. 